OPEN ACCESS

Edited by:

Eric Boué-Grabot,

Université de Bordeaux, France

Reviewed by:

Frank Kirchhoff,

Saarland University, Germany

Simona Candiani,

University of Genoa, Italy

*Correspondence:

Javier Gualix

jgualix@ucm.es

Specialty section:

This article was submitted to

Cellular Neurophysiology,

a section of the journal

Frontiers in Cellular Neuroscience

Received: 18 February 2019 Accepted: 02 May 2019 Published: 17 May 2019

Citation:

Miras-Portugal MT,

Menéndez-Méndez $A$, Gómez-Villafuertes $R$, Ortega F Delicado EG, Pérez-Sen $R$ and Gualix J (2019) Physiopathological Role of the Vesicular Nucleotide

Transporter (VNUT) in the Central Nervous System: Relevance of the Vesicular Nucleotide Release as a Potential Therapeutic Target. Front. Cell. Neurosci. 13:224. doi: 10.3389/fncel.2019.00224

\section{Physiopathological Role of the Vesicular Nucleotide Transporter (VNUT) in the Central Nervous System: Relevance of the Vesicular Nucleotide Release as a Potential Therapeutic Target}

\author{
María T. Miras-Portugal1,2,3, Aida Menéndez-Méndez1,2,3, Rosa Gómez-Villafuertes ${ }^{1,2,3}$, \\ Felipe Ortega ${ }^{1,2,3}$, Esmerilda G. Delicado ${ }^{1,2,3}$, Raquel Pérez-Sen ${ }^{1,2,3}$ and Javier Gualix ${ }^{1,2,3 *}$ \\ ${ }^{1}$ Departamento de Bioquímica y Biología Molecular, Facultad de Veterinaria, Universidad Complutense de Madrid, Madrid, \\ Spain, ${ }^{2}$ Instituto Universitario de Investigación en Neuroquímica, Universidad Complutense de Madrid, Madrid, Spain, \\ ${ }^{3}$ Instituto de Investigación Sanitaria del Hospital Clínico San Carlos, Madrid, Spain
}

Vesicular storage of neurotransmitters, which allows their subsequent exocytotic release, is essential for chemical transmission in the central nervous system. Neurotransmitter uptake into secretory vesicles is carried out by vesicular transporters, which use the electrochemical proton gradient generated by a vacuolar $\mathrm{H}^{+}$-ATPase to drive neurotransmitter vesicular accumulation. ATP and other nucleotides are relevant extracellular signaling molecules that participate in a variety of biological processes. Although the active transport of nucleotides into secretory vesicles has been characterized from the pharmacological and biochemical point of view, the protein responsible for such vesicular accumulation remained unidentified for some time. In 2008, the human SLC17A9 gene, the last identified member of the SLC17 transporters, was found to encode the vesicular nucleotide transporter (VNUT). VNUT is expressed in various ATP-secreting cells and is able to transport a wide variety of nucleotides in a vesicular membrane potential-dependent manner. VNUT knockout mice lack vesicular storage and release of ATP, resulting in blockage of the purinergic transmission. This review summarizes the current studies on VNUT and analyzes the physiological relevance of the vesicular nucleotide transport in the central nervous system. The possible role of VNUT in the development of some pathological processes, such as chronic neuropathic pain or glaucoma is also discussed. The putative involvement of VNUT in these pathologies raises the possibility of the use of VNUT inhibitors for therapeutic purposes.

Keywords: VNUT, vesicular ATP release, purinergic signaling, neuropathic pain, glaucoma, clodronate 


\section{INTRODUCTION}

Chemical transmission at the synapse plays a central role in cellular communication in both the central and peripheral nervous system. This process requires the previous storage of neurotransmitters into synaptic vesicles and their subsequent release through $\mathrm{Ca}^{2+}$-dependent exocytosis. The released neurotransmitters interact with specific receptors on the plasma membrane of target cells, thus triggering intracellular signals. Vesicular neurotransmitter transporters (VNTs) are the proteins responsible for the storage of these compounds into synaptic vesicles, thus determining the amount of neurotransmitter available to be released by exocytosis and, therefore, are essential components of chemical transmission in the nervous system (Blakely and Edwards, 2012; Omote and Moriyama, 2013; Omote et al., 2016). Different types of transporters are known to be involved in the uptake of neurotransmitters into synaptic vesicles. These include the vesicular glutamate transporters (VGLUTs), vesicular monoamine transporters (VMATs), vesicular acetylcholine transporter (VAChT), and vesicular inhibitory amino acid transporter (VIAAT) (Eiden et al., 2004; Gasnier, 2004; Reimer, 2013). These vesicular transporters are active transport systems that mediate the accumulation of their respective neurotransmitters by means of an electrochemical proton gradient $\left(\Delta \mu \mathrm{H}^{+}\right)$across the vesicular membrane, which is generated by a vacuolar $\mathrm{H}^{+}$-ATPase (V-ATPase) (Njus et al., 1986; Whittaker, 1987). $\Delta \mu \mathrm{H}^{+}$is composed of a proton gradient $(\Delta \mathrm{pH}$, lumen acidic) and the membrane potential $(\Delta \Psi$, lumen-positive). Vesicular neurotransmitter transporters use the chemical $(\Delta \mathrm{pH})$, electrical $(\Delta \Psi)$ or both components of $\Delta \mu \mathrm{H}^{+}$ as driving forces to mediate transport of neurotransmitters against their concentration gradient (Chaudhry et al., 2008).

ATP is a relevant chemical transmitter released from neurons and non-neuronal cells. In the extracellular space, this nucleotide undergoes successive hydrolysis by ectonucleotidases and both ATP and some of its enzymatic breakdown products (ADP and adenosine) can interact with specific cell-surface purinoceptors (Burnstock, 2007b). In the nervous system, purinergic signaling is involved in a great variety of either physiological or pathological processes such as mechanosensory transduction, central control of autonomic functions, glia-glia and neuronalglial interaction, pain, trauma, ischemia or inflammation. In addition, extracellular nucleotides exert potent long-term effects in cell proliferation, growth and development (Burnstock, 2007a; Abbracchio et al., 2009; Burnstock et al., 2011). In spite of the relatively well-known features of the signaling cascade after ATP secretion and activation of the purinergic receptors, the mechanism by which ATP is released from cells remains less understood. There is compelling evidence for neuronal exocytotic release of ATP (Richardson and Brown, 1987; Sawynok et al., 1993; Jo and Schlichter, 1999; Pankratov et al., 2006, 2007; Tompkins and Parsons, 2006) and studies also support a vesicular release of ATP from glial cells (Pascual et al., 2005; Pankratov et al., 2006; Bowser and Khakh, 2007; Pangrsic et al., 2007; Zhang et al., 2007; Parpura and Zorec, 2010; Lalo et al., 2014), although additional mechanisms of nucleotide release through ATP-binding cassette transporters, pannexin or connexin hemichannels, voltagedependent anion channels or P2X7 receptors cannot be ruled out (Lazarowski, 2012; Baroja-Mazo et al., 2013). Consistent with this, the determination of the mechanism and physiological relevance of vesicular ATP storage and its exocytotic release, that is, vesicular ATP release, appear to be critical for the full understanding of purinergic chemical transmission at the nervous system.

In the past decades, it has been recognized that ATP is a common constituent of secretory vesicles (Winkler, 1976; Holmsen and Weiss, 1979; Hutton et al., 1983; Njus et al., 1986; Johnson, 1988). The presence of an active transport mechanism that mediate nucleotide accumulation in a $\Delta \Psi$-dependent manner has been described in adrenal medulla chromaffin granules and the kinetic behavior, solute specificity and pharmacology of the nucleotide vesicular transporter have been extensively analyzed in this secretory vesicle model (Kostron et al., 1977; Aberer et al., 1978; Weber and Winkler, 1981; Bankston and Guidotti, 1996; Gualix et al., 1996, 1997, 1999a). When transport was assayed using a wide range of substrate concentrations, complex non-hyperbolic saturation curves were obtained. This complex dependence of transport capacity with substrate concentration was explained on the basis of a mnemonical kinetic model (Gualix et al., 1996, 1997). The mnemonic kinetic behavior of the nucleotide vesicular transporter was further corroborated by flow cytometry analysis of fluorescent nucleotide analogs incorporation into single chromaffin granules (Gualix et al., 1999a). Another remarkable feature of the nucleotide vesicular transporter in chromaffin granules is its low specificity (Aberer et al., 1978; Weber and Winkler, 1981; Bankston and Guidotti, 1996; Gualix et al., 1996, 1997), this transporter being able to internalize a wide diversity of nucleotides such as ATP, ADP, AMP, GTP, and UTP (Figure 1A), as well as the diadenosine polyphosphates $\left(A p_{n} A\right)$, a group of dinucleotides that are also constituents of secretory vesicles (Rodriguez del Castillo et al., 1988; Pintor et al., 1992a,b,c) and can be detected in the extracellular media both under basal conditions (Gualix et al., 2014) or after stimulation of the cells with depolarizing agents or secretagogues (Pintor et al., 1992a,c). Nucleotide uptake into chromaffin granules is significantly reduced in the presence of atractyloside (Figure 1B), a compound previously described as an inhibitor of the mitochondrial ADP/ATP exchanger, and the anion transport inhibitor 4,4'-diisothiocyanatostilbene-2,2' -disulfonic acid (DIDS) (Kostron et al., 1977; Aberer et al., 1978; Weber and Winkler, 1981; Bankston and Guidotti, 1996; Gualix et al., 1996, 1997). A nucleotide vesicular transporter with strong similarities to that described in chromaffin granules can be also observed in cholinergic synaptic vesicles isolated from Torpedo marmorata electric organ and brain synaptic vesicles. Again, several different nucleotides can be incorporated into the vesicles through this vesicular transporter (Luqmani, 1981; Gualix et al., 1999b), which also exhibits a complex kinetic behavior that can be explained by means of a mnemonical model (Gualix et al., 1999b). As occurs in chromaffin granules, nucleotide transport into synaptic vesicles is affected by atractyloside and DIDS, although the compound that showed more effectivity to reduce ATP uptake into the 
A

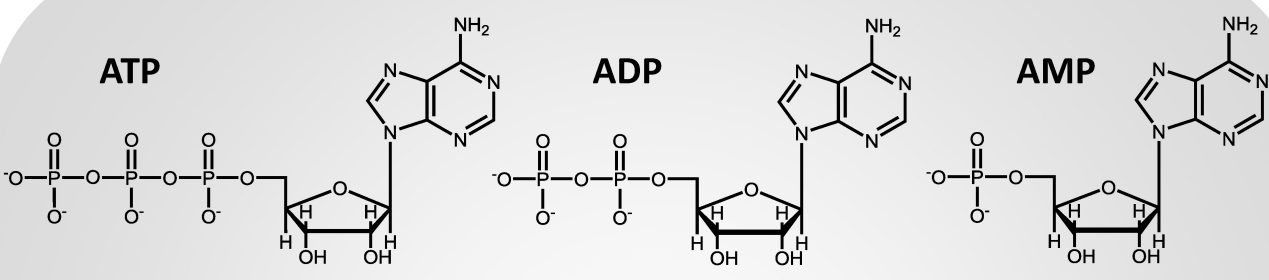<smiles>Nc1nc2c(ncn2C(O)[C@H](O)O[C@H](O)[C@@H](O)COP(=O)([O-])OP(=O)([O-])OP(=O)([O-])[O-])c(=O)[nH]1</smiles>

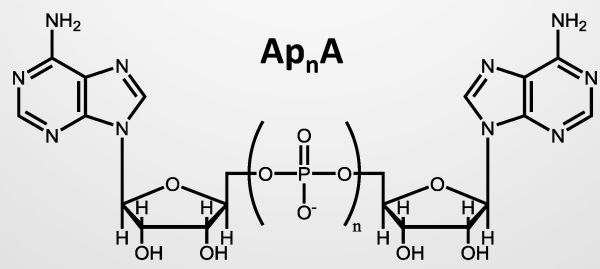

B<smiles>Cc1cc(-c2ccc(N=Nc3ccc4c(S(=O)(=O)O[Na])cc(S(=O)(=O)O[Na])c(N)c4c3O)c(C)c2)ccc1N=Nc1ccc2c(S(=O)(=O)O[Na])cc(S(=O)(=O)O[Na])c(N)c2c1O</smiles><smiles>O=S(=O)(O[Na])c1cc(N=C=S)ccc1/C=C/c1ccc(N=C=S)cc1S(=O)(=O)O[Na]</smiles><smiles>CC(=O)CC(=O)[O-]</smiles>

Acetoacetate

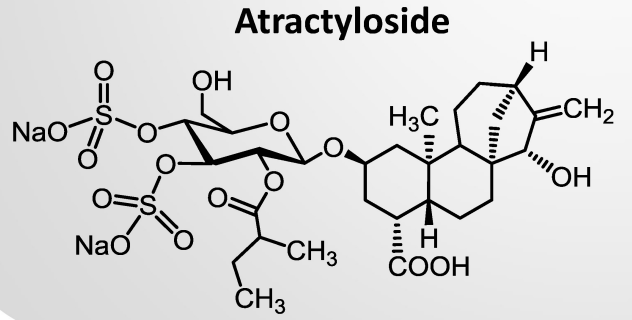<smiles>O=P(O)(O)C(Cl)(Cl)P(=O)(O)O[Na]</smiles>

Clodronate

FIGURE 1 | Chemical structure of the main transport substrates (A) and inhibitors (B) of the vesicular nucleotide transporter.

vesicles was Evans blue (Figure 1B; Gualix et al., 1999b), a dye which was previously described as a potent inhibitor of the vesicular glutamate transporter (Roseth et al., 1995). However, in spite of the accumulating evidence of the presence of an active mechanism of nucleotide transport into secretory vesicles, such as synaptic vesicles and adrenal chromaffin granules, the protein responsible for the nucleotide vesicular accumulation remained unidentified for some time. 
Solute carrier 17 (SLC17) type I inorganic phosphate transporters are a group of structurally related proteins that mediate the transmembrane transport of organic anions. Members of this transporter family include the three identified isoforms of the vesicular glutamate transporter VGLUT1 (SLC17A7), VGLUT2 (SLC17A6), and VGLUT3 (SLC17A8) (Reimer, 2013). In 2008, SLC17A9, the last identified member of this family was found to encode the vesicular nucleotide transporter (VNUT). Northern blot analysis revealed that SLC17A9 gene is expressed in several organs, being especially abundant in the brain and the adrenal gland, regions where nucleotide vesicular transport might be relevant (Sawada et al., 2008). Moreover, in the adrenal gland, the SLC17A9 protein is specifically expressed in the medulla, where it is associated with chromaffin granules, as revealed by immunohistochemistry, immunoelectron microscopy and Western blot (Sawada et al., 2008). These data are compatible with the hypothesis that SLC17A9 could be responsible for the granular storage of the nucleotides. The human SLC17A9 protein was expressed, purified and incorporated into liposomes and an internal positive $\Delta \psi$ was generated by diffusion of $\mathrm{K}^{+}$into the liposomes by the addition of valinomycin, in order to supply a driving force for nucleotide uptake. As anticipated, the SLC17A9 protein actively transported ATP at the expense of $\Delta \psi$ but not of $\Delta \mathrm{pH}$. This protein carried several nucleotides with the following order of efficacy: ATP $>$ UTP $>$ GTP $>$ ITP, ADP > > AMP. Adenosine cannot be transported by the SLC17A9 protein, whereas the diadenosine polyphosphate $\mathrm{Ap}_{3} \mathrm{~A}$ is a good transport substrate. The substrate selectivity of the SLC17A9 protein approximately matches the nucleotide content of the organelles that store ATP (Sawada et al., 2008). Additionally, SLC17A9 does not transport substrates of other members of the SLC17 family such as glutamate, aspartate, or hippuric acid, which indicates that the SLC17A9 protein is a carrier that specifically recognizes a variety of nucleotides as transport substrates. SLC17A9-mediated ATP transport is inhibited by DIDS and Evans blue (Sawada et al., 2008). Atractyloside is also a partial inhibitor but only when $\mathrm{Mg}^{2+}$ is present in the assay medium. These characteristics are similar, if not identical, to those observed for the transport of nucleotides to chromaffin granules and synaptic vesicles. Moreover, SLC17A9 protein is endogenously expressed by PC12 pheochromocytoma cells, where it is associated with secretory granules. Suppression of SLC17A9 gene expression by RNA interference (RNAi) strongly decreased vesicular storage and release of ATP from PC12 cells. Taken together, all these results demonstrate that SLC17A9 encodes VNUT (Sawada et al., 2008; Moriyama et al., 2017). When mouse VNUT protein was purified and reconstituted in liposomes (Larsson et al., 2012) it exhibited similar functional properties to the previously characterized human orthologue (Sawada et al., 2008), thus indicating that SLC17A9 also encodes the VNUT in rodents. An additional evidence of the essential role of this protein in the vesicular storage of nucleotides is that the vesicular release of ATP is lost from neurons and neuroendocrine cells of VNUT knockout $\left(V N U T^{-/-}\right)$mice (Sakamoto et al., 2014; Masuda et al., 2016; Nakagomi et al., 2016; Moriyama et al., 2017).

\section{VNUT DISTRIBUTION IN NEURONAL AND GLIAL POPULATIONS OF THE CENTRAL NERVOUS SYSTEM}

\section{Expression and Distribution of VNUT in the Brain}

The seminal work of Sawada et al. (2008) showed the expression of VNUT in human and mouse brain but its cellular and subcellular distribution was not known.

Allen Mouse Brain Atlas provides a comprehensive atlas of gene expression in the adult $\mathrm{C} 57 \mathrm{BL} / 6 \mathrm{~J}$ mouse brain. Data were generated using automated high-throughput procedures for in situ hybridization and data acquisition (Lein et al., 2007), and are publicly accessible online ${ }^{1}$. As shown in Figure 2, VNUT transcript is widely expressed throughout the adult mouse brain, with a prominent expression found in areas such as the hippocampus or the cerebellum.

Immunoperoxidase labeling of rat brain tissue also showed that VNUT is widely distributed throughout the brain with particular strong VNUT immunoreactivity in the cerebellum, the hippocampus and the olfactory bulb (Larsson et al., 2012).

\section{VNUT in the Hippocampus}

Figure 3 shows immunofluorescence images demonstrating the presence of VNUT in cultured mouse hippocampal neurons at 7 days in vitro.

Vesicular nucleotide transporter immunofluorescence could be detected in the soma and neurites of cultured hippocampal neurons, which also showed VNUT-dependent ATP release, as $\mathrm{K}^{+}$-evoked ATP release was attenuated by RNAi-mediated knockdown of VNUT (Larsson et al., 2012). The staining pattern of VNUT in the hippocampal neurons only partially overlapped with the presynaptic terminal markers synaptophysin and synaptotagmin 1, thus indicating that VNUT was located in different neuronal compartments. The analysis of the subcellular localization of VNUT in the hippocampal neuropil by immunogold labeling and electron microscopy showed that the nucleotide transporter is associated with synaptic vesicles in both excitatory and inhibitory terminals (Larsson et al., 2012). Moreover, VNUT immunoreactivity can be also detected in preterminal axons, where it was mainly located to the axoplasm as opposed to near the plasma membrane, indicating that VNUTpossessing vesicles are undergoing axonal transport (Larsson et al., 2012). VNUT also appears to be associated with vesicular structures in postsynaptic dendritic spines in the hippocampal formation. Although the role of the postsynaptically localized VNUT have to be clarified in further studies, authors hypothesize that postsynaptic spines can be an additional potential source of extracellular ATP, which may act as a retrograde signal, thus modulating presynaptic transmitter release (Larsson et al., 2012). Immunoisolation experiments showed that some, but not all, VGLUT1-possessing synaptic vesicles also contain VNUT, thus indicating that ATP is stored only in a subpopulation of glutamatergic vesicles. Analysis of immunogold labeling in

\footnotetext{
${ }^{1}$ http://portal.brain-map.org/
} 


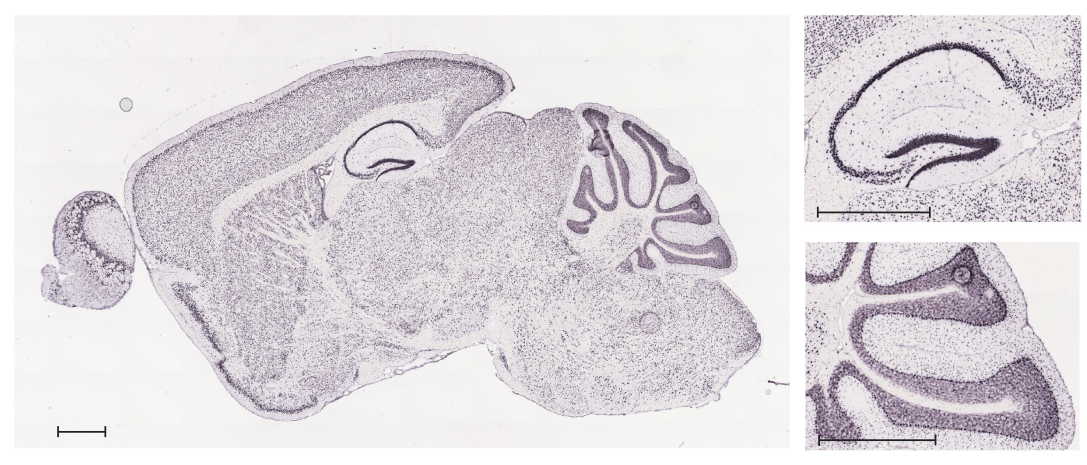

FIGURE 2 | In situ hybridization analysis of VNUT transcript expression in a sagittal section of adult mouse brain. Inserts show magnification of the hippocampal and cerebellar areas. Scale bar: $850 \mu \mathrm{m}$. Image credit: Allen Mouse Brain Atlas (http://mouse.brain-map.org/gene/show/86822). Image is reproduced with permission of the copyright holders.
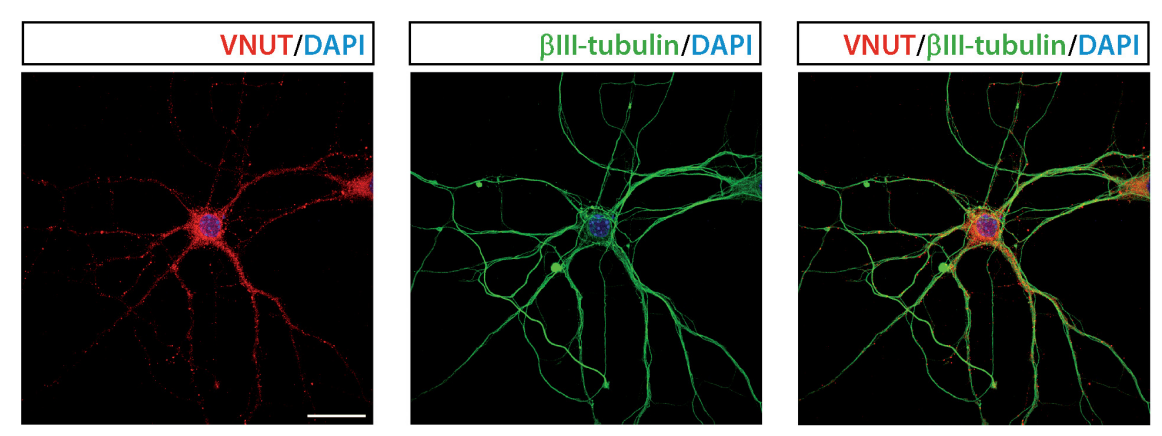

FIGURE 3 | Vesicular nucleotide transporter is expressed by cultured hippocampal neurons. Representative immunofluorescence images showing immunostaining for VNUT (red) and the cytoskeletal protein $\beta$ III-tubulin (green) in cultured hippocampal neurons at 7 days in vitro. The nuclei are counterstained with DAPI (blue). Scale bar: $20 \mu \mathrm{m}$. Adapted from Menéndez Méndez (2017). Images are reproduced with permission of the copyright holders.

hippocampal inhibitory terminals suggested that a similar partial segregation exists between VNUT- and VGAT-possessing vesicles (Larsson et al., 2012). Taken together, all these data indicate that VNUT may confer a purinergic phenotype to hippocampal neurons by establishing an exocytotically releasable vesicular pool of ATP. Hippocampal neurons from $V N U T^{-/-}$mice completely loss their capacity to release ATP in response to $\mathrm{K}^{+}$stimulation (Sakamoto et al., 2014), which is an additional confirmation of the essential role of VNUT in the neuronal vesicular storage and vesicular release of ATP in the hippocampus.

\section{VNUT in the Cerebellum}

When localization of VNUT was analyzed by immunoperoxidase labeling in the rat brain, particularly strong immunoreactivity was observed in the cerebellar cortex. VNUT immunolabeling was detected in the somatodendritic extent of Purkinje cells, being also relevant throughout the molecular layer (Larsson et al., 2012).

Further studies have shown that cultured cerebellar granule neurons express a functional VNUT that participates in the exocytotic release of ATP from these cells (Menendez-Mendez et al., 2017). VNUT can be detected by western blotting and immunofluorescence in the cultured granule neurons, which release ATP in a $\mathrm{Ca}^{2+}$-dependent manner, as stimulation of the cells with the calcium-selective ionophore ionomycin induces a significant increase of extracellular ATP (MenendezMendez et al., 2017). Exocytosis of ATP-containing vesicles can be visualized by fluorescence microscopy using quinacrine. This acidophilic antimalarial drug interacts with ATP stored in vesicles and has been extensively used as a fluorescent marker of intracellular ATP storage sites (Orriss et al., 2009; Liu et al., 2016). When granule cells were loaded with quinacrine, a punctate staining was observed, which appeared not only throughout the soma but was also evident in cell prolongations, thus indicating the presence of numerous ATP enriched vesicles in the granule neurons. Depolarization of the cells with $\mathrm{K}^{+}$reduced quinacrine-associated fluorescence in granule cells, showing that they release ATP via $\mathrm{Ca}^{2+}$-dependent exocytosis (Menendez-Mendez et al., 2017). Ionomicin-induced ATP release was reduced when granule neurons were treated with the VNUT inhibitor Evans blue, thus indicating the involvement of VNUT in the vesicular storage and release of ATP. Moreover, immunofluorescence assays showed the colocalization of the vesicular protein synaptophysin and VNUT immunostaining in granule neurons, which further supports the exocytotic nature of ATP release (Menendez-Mendez et al., 2017). However, co-localization of VNUT and the synaptic vesicle marker was incomplete, suggesting that VNUT may be 
also present in another type of storage vesicles or subcellular structures. The subcellular distribution of VNUT in cerebellar granule neurons was analyzed by the use of specific axonal and somatodendritic markers, such as the pan-axonal neurofilament marker SMI 312 and the microtubule-associated protein 2 (MAP2), respectively. VNUT showed co-localization with both subcellular markers, suggesting that this transporter exists both pre- and post-synaptically in the granule cells. The presence of VNUT in postsynaptic domains was confirmed by the clear co-localization of the transporter protein with the postsynaptic density protein 95 (PSD95). Interestingly, the co-localization of VNUT and the lysosomal marker LAMP-1 in certain cytosolic areas indicated that VNUT can be also found in lysosomes (Menendez-Mendez et al., 2017).

The glutamatergic phenotype of cerebellar granule neurons requires the vesicular storage of glutamate through VGLUTs, of which the most abundant isoform is VGLUT1. Immunofluoresecence assays showed a weak co-localization between VNUT and VGLUT1 in the granule neurons, suggesting that ATP- and glutamate-containing vesicle pools are segregated in these cells (Menendez-Mendez et al., 2017). Nevertheless, it should be taken into account that these studies were performed in vitro, in cultured granule cells. To assess whether such distribution also reflects the situation in vivo, slices of mouse cerebellum were immunolabeled with antibodies to VNUT and VLGUT1. These two vesicular transporters clearly showed a non-overlapping distribution with only a few examples of colocalization between VGLUT and VNUT in both the molecular or granular layers, which was consistent with the results obtained in cultured cells (Menendez-Mendez et al., 2017).

Cerebellar sections of P5 and P15 mice were used to analyze the distribution of VNUT during the postnatal development of the cerebellar cortex. At P5 stage, cortical layers of the cerebellum are not well defined and immature granule neurons are still migrating from the external to the internal granular layer, where they reach their final location. At this stage, VNUT was abundantly expressed and can be found in granule cell precursors and immature neurons that have not completely differentiated (Menendez-Mendez et al., 2017), suggesting a possible role of this transporter in the initial stages of granule cells maturation. Committed granule cells become mature neurons during the subsequent development of the cerebellum. Consistent with this, markers of neuronal progenitors and immature neurons are dramatically reduced at P15 stage. Nevertheless, VNUT expression persisted at this stage (Menendez-Mendez et al., 2017), indicating the relevance of VNUT during the commitment and differentiation of granule cells. These results correlate with the observations in vitro. VNUT expression could be detected from the first day of culture, when cerebellar granule neurons are still immature, persisting once the cells have matured and established synaptic contacts (Menendez-Mendez et al., 2017). Although further studies are required to fully understand the role of VNUT in the maturation of the granule cells and the development of the cerebellum, these findings, showing the localization and activity of VNUT in cerebellar granule neurons in vitro and their correlation with the situation in vivo, opens exciting new questions that need to be addressed in the future.
Double immunolabeling with antibodies against calbindin and VNUT revealed that the vesicular nucleotide transported is located adjacent to Purkinje neurons in P15 cerebellar sections, showing a filamentous morphology. Besides, co-localization between VNUT and the glial fibrillary acidic protein (GFAP) could be observed (Figure 4A). This staining pattern is consistent with the presence of VNUT in Bergmann glia, a population of radial glia present in the Purkinje cell layer. Moreover, the same pattern of VNUT immunolabeling persisted in the adult stage (Figure 4B), thus indicating that VNUT is present in this type of glial cells both in the advanced stages of cerebellar development and in the adult cerebellum. Bergmann glia has been postulated as one of the neurogenic populations in the cerebellum, as expression of neural stem cell markers, such as Sox2, a transcription factor that plays a key role in neurogenesis during the development of the nervous system, has been described in these cells (Sottile et al., 2006; Alcock et al., 2009). Presence of VNUT in these putative stem cells also supports a potential role of this vesicular transporter in the development of the cerebellum.

\section{VNUT in Midbrain Dopaminergic Neurons}

Immunohistochemical studies showed the presence of VNUT in tyrosine hydroxylase (TH)-positive dopaminergic neurons of the substantia nigra and ventral tegmental area of the midbrain (Ho et al., 2015). All TH-positive dopaminergic neurons in these areas were VNUT-positive. Nevertheless, expression of VNUT was not restricted to dopaminergic neurons, as VNUTpositive TH-negative cells can be detected in the substantia nigra and other regions of the brain (Ho et al., 2015). These findings, together with the fact that VNUT is expressed by retinal dopaminergic neurons, which incorporate ATP into vesicles and release ATP when stimulated (see below), indicate that the machinery necessary for vesicular ATP release is present in dopaminergic neurons from different regions of the central nervous system, and that these dopaminergic neurons can be a source of extracellular ATP and its bioactive breakdown products (Ho et al., 2015). These purinergic ligands would mediate their actions trough purinoceptors which are pre-synaptically expressed on dopaminergic neurons and co-expressed with dopamine receptors on neurons in regions that receive the dopaminergic input (Amadio et al., 2007; Morin and Di Paolo, 2014). As dopaminergic neurons in the midbrain are involved in the modulation of a wide range of behaviors, such as motor control, motivation and reward responses (Wise, 2008; Joshua et al., 2009; Cachope and Cheer, 2014), it is likely that purinergic transmission could play a role in these processes. Likewise, purinergic neurotransmission could have a role in neurological disorders involving dysregulation of midbrain dopaminergic pathways, such as Parkinson's disease (Chinta and Andersen, 2005; Hracsko et al., 2011).

\section{VNUT in Glial Cells VNUT in Astrocytes}

Several studies have shown that astrocytes respond to neurotransmitters and release different gliotransmitters, including ATP, which can trigger propagation of $\mathrm{Ca}^{2+}$ waves 


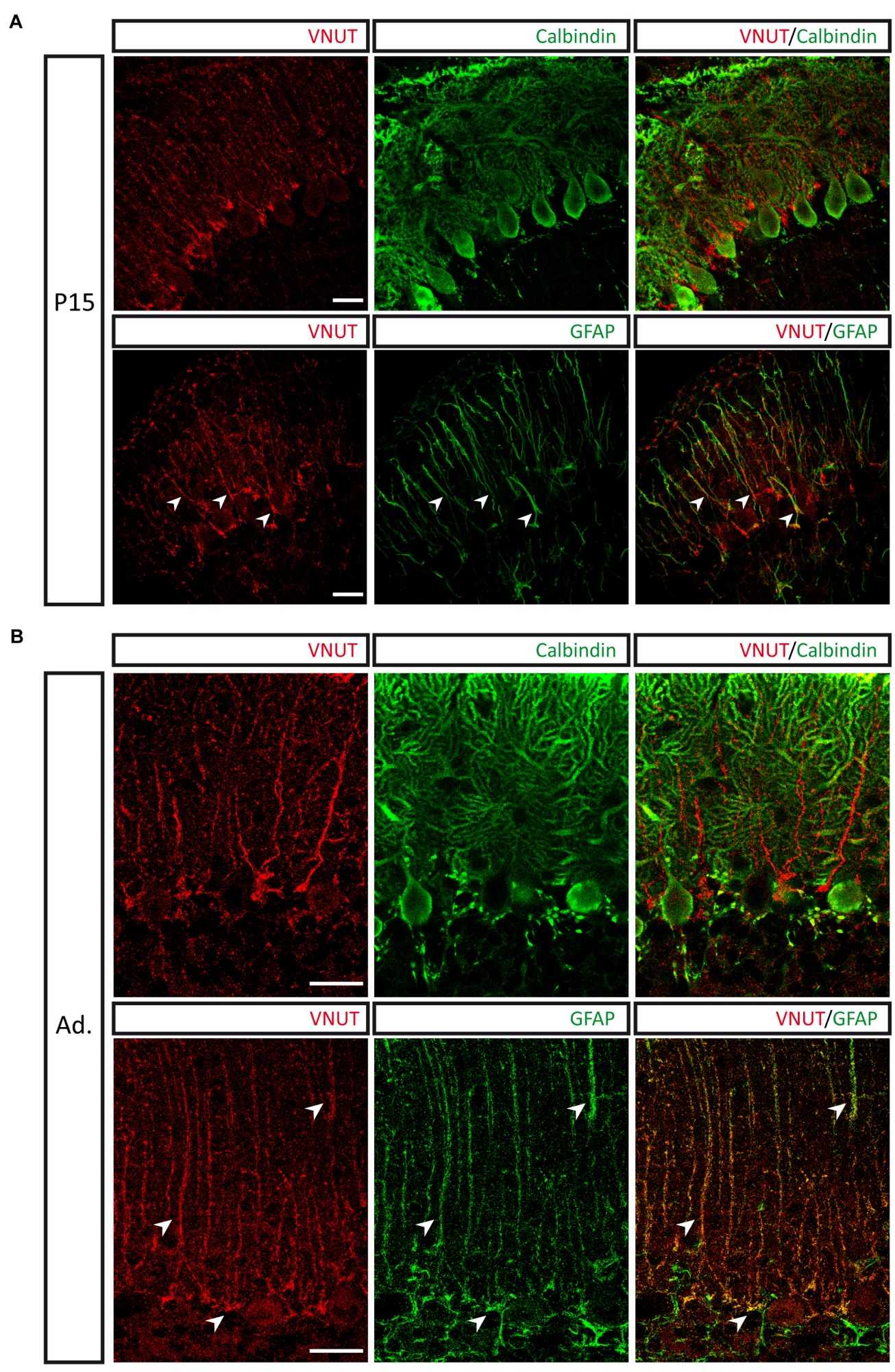

FIGURE 4 | Presence of VNUT in Bergmann glia. Representative immunofluorescence images showing double immunostaining for VNUT (red) and calbindin or GFAP (green) in cerebellar sections of P15 (A) and adult (B) mice. Arrowheads indicate co-localization of the immunoreactivity for VNUT and GFAP. Scale bar: $20 \mu \mathrm{m}$. Adapted from Menéndez Méndez (2017). Images are reproduced with permission of the copyright holders. 
in these cells and modulate the activity of surrounding neurons (Stout et al., 2002; Coco et al., 2003; Newman, 2003; Zhang et al., 2003; Bowser and Khakh, 2007; Chen et al., 2013). However, the precise mechanism by which astrocytes release ATP are not well understood and both $\mathrm{Ca}^{2+}$-dependent exocytosis (Coco et al., 2003; Pascual et al., 2005; Pangrsic et al., 2007; Parpura and Zorec, 2010; Lalo et al., 2014) and non-vesicular release pathways (Stout et al., 2002; Suadicani et al., 2006, 2012; Liu et al., 2008) have been described. Lysosomes can be a relevant source of vesicular ATP release from astrocytes, with the fusion of lysosomal and plasma membranes leading to ATP exocytosis (Zhang et al., 2007; Verderio et al., 2012).

Vesicular nucleotide transporter is expressed in C6 glioma cells and primary cultures of cortical astrocytes, where it is mainly associated to lysosomes, as demonstrated by the co-localization of VNUT-EGFP with lysosomal markers (Oya et al., 2013). Interestingly, VNUT-associated lysosomes release their content in response to elevations of the intracellular $\mathrm{Ca}^{2+}$ concentration, but they do not completely collapse into the plasma membrane after lysosomal exocytosis, as VNUT remains associated with the secretory lysosome and failed to spread into the plasma membrane, suggesting that lysosomes retain their spherical structure for a long time after fusion to plasma membrane. Such "kiss and stay" mechanism is quite different from the behavior of synaptic or dense-core vesicles, which easily spread into the plasma membrane during fusion events (Oya et al., 2013). ATP uptake into the secretory lysosomes decreased by pharmacological inhibition of VNUT by Evans blue. Moreover, silencing of VNUT expression by siRNA or inhibition of VNUT function by Evans blue reduced the amount of ATP released by the cells, whereas overexpression of VNUT increased it. Collectively, these data demonstrate the implication of VNUT in ATP storage in secretory lysosomes in astrocytes and its relevant role in astrocytic ATP release by lysosomal exocytosis (Oya et al., 2013). VNUT co-localize with the lysosomal marker LAMP3 in rat optic nerve head astrocytes that release lysosomal ATP after stimulation of the toll-like receptor 3 (TLR3), which is an additional evidence supporting the role of VNUT in the storage of ATP in secretory lysosomes in astrocytes (Beckel et al., 2018).

Astrocytes residing near the brainstem ventral surface (central respiratory chemosensitive area) respond to physiological reductions in $\mathrm{pH}$ with elevations in intracellular $\mathrm{Ca}^{2+}$ and ATP release. ATP stimulates the brainstem respiratory network, thus contributing to adaptive changes in lung ventilation. In terms of their sensitivity to $\mathrm{pH}$, ventral brainstem astrocytes clearly differ from astrocytes that reside in other parts of the brain, such as cerebral cortex astrocytes, which indicates that these cells are functionally specialized (Kasymov et al., 2013). Compared to cortical astrocytes, ventral brainstem astrocytes showed increased levels of expression of genes encoding proteins associated with vesicular ATP transport and vesicular fusion, including VNUT (Kasymov et al., 2013), which suggests that astrocytes of the brainstem chemosensitive area are able to respond to acidification with enhanced vesicular release of ATP. Moreover, ATP released from astrocytes, possibly by the exocytosis of VNUTpossesing vesicular compartments, is involved in sensing of physiological changes in oxygen concentration in the brain (Angelova et al., 2015).

ATP derived from astrocytes modulates depressive behaviors in mice (Cao et al., 2013). In this sense, VNUT-dependent ATP release from astrocytes seems to play a pivotal role in the therapeutic effect of the anti-depressant fluoxetine (Kinoshita et al., 2018). Fluoxetine increases exocytotic ATP release in primary cultures of hippocampal astrocytes. Fluoxetine-induced ATP release was significantly reduced in astrocytes obtained from VNUT-knockdown mice, indicating that fluoxetine, at least in part, stimulates the release of ATP by VNUT-dependent exocytosis (Kinoshita et al., 2018). Fluoxetine-induced antidepressive behavior was decreased in VNUT-knockdown mice and, relevantly, the anti-depressive effects of fluoxetine were dependent on astrocytic VNUT, as demonstrated in mice with selective knockout or overexpression of the VNUT gene in astrocytes. A decrease or increase of VNUT in astrocytes, resulted in a decrease or increase in the anti-depressive effects induced by fluoxetine, respectively. These findings demonstrate that fluoxetine acts on astrocytes and mediates its anti-depressive effect by increasing VNUT-dependent ATP exocytosis from these cells (Kinoshita et al., 2018). Released ATP and its metabolite adenosine act on $\mathrm{P}_{2} \mathrm{Y}_{11}$ and adenosine A2b receptors expressed by astrocytes, inducing an increase in brain-derived neurotrophic factor (BDNF), which is considered to have a relevant role in the therapeutic action of anti-depressants (Kinoshita et al., 2018).

\section{VNUT in the Microglia}

Microglial cells constitute the resident immune cell population of the mammalian central nervous system. These cells monitor environmental changes and act as damage sensors within the brain. Any type of injury or pathological process induces the activation of the microglia, which change their morphology, migrate to the site of injury, proliferate, produce/release several substances that affect pathological processes, or even phagocytose damaged cells or debris to restore the brain homeostasis (Kettenmann et al., 2011). Extracellular nucleotides are relevant mediators that regulate the function of the microglia and, consequently, purinoceptor-mediated microglial responses have received much attention (Calovi et al., 2018). Microglia release ATP in response to different stimuli, such as ATP or glutamate (Liu et al., 2006; Dou et al., 2012). The mechanisms involved in ATP release from microglia remain unclear, although participation of connexin 43 (Cx43) hemichannels has been described (Ma et al., 2014).

Vesicular nucleotide transporter was found to be expressed in vesicular-like structures in primary cultured microglia and exhibited no co-localization with lysosomes (Imura et al., 2013). When cells where incubated with the fluorescent ATP analog $2^{\prime} / 3^{\prime}$-O-(N-Methyl-anthraniloyl)-adenosine-5' -triphosphate (MANT-ATP), the existence of many ATP-possessing vesicular structures could be observed. Microglia release ATP in an exocytotic manner: when cells were stimulated with ionomycin they released ATP and such release was dependent on $\mathrm{Ca}^{2+}$, vesicular $\mathrm{H}^{+}$-ATPase and soluble $\mathrm{N}$-ethylmaleimide sensitive factor attachment protein receptors (SNAREs), but independent on connexin/pannexin hemichannels. Additionally, exocytotic 
events of ATP-containing vesicles could be visualized by quinacrine-based TIRF microscopy in the microglial cell line MG5 (Imura et al., 2013). Ionomycin-induced ATP release from microglial cells was dependent upon VNUT, as release was significantly reduced when cells were treated with VNUT-siRNA. These findings demonstrated that microglia possess functional VNUT by which microglial cells store and release ATP in an exocytotic process (Imura et al., 2013). Moreover, stimulation of MG5 cells with the bacterial endotoxin lipopolysaccharide (LPS) significantly increased ionomycin-evoked ATP release, which was associated with an increase in VNUT expression. The increase in ATP release by LPS was abolished by the knockdown of VNUT (treatment of the cells with VNUT siRNA), indicating that the increase in VNUT by LPS should be responsible for the enhancement of the ATP release in microglial MG5 cells. This could be of relevance because, during infections or brain injuries, microglia could increase exocytotic ATP release by increasing VNUT (Imura et al., 2013).

Methylmercury (MeHg) is a well-known environmental pollutant that easily crosses the blood-brain barrier, inducing severe neuronal damage. It has been described that cultured microglia sense low concentrations of $\mathrm{MeHg}$ and release ATP in response to this neurotoxicant (Shinozaki et al., 2014). MeHgevoked ATP release is significantly reduced by treatment with the botulinum toxin $\mathrm{A}$, a toxin that cleaves synaptosomalassociated proteins (SNAPs), thereby preventing exocytosis. Moreover, microglia cultures prepared from VNUT knockout mice showed no ATP release when exposed to $\mathrm{MeHg}$, in contrast to the significant ATP release from wild-type microglia. These results indicate that $\mathrm{MeHg}$ stimulates the exocytic release of ATP from microglial cells via a VNUT-dependent pathway (Shinozaki et al., 2014). The microglia-derived ATP in turn stimulates $\mathrm{P}_{2} \mathrm{Y}_{1}$ receptors in astrocytes, which induces the release of interleukin-6 (IL-6), thus protecting neurons against $\mathrm{MeHg}$. These neuroprotective effects were observed in organotypic slices from the hippocampus of wild-type mice, but not in slices obtained from VNUT knockdown mice, where $\mathrm{MeHg}$ failed to induce ATP release or IL-6production, which resulted in neuronal damage induced by $\mathrm{MeHg}$ (Shinozaki et al., 2014).

\section{ROLE OF VNUT IN CENTRAL NERVOUS SYSTEM PHYSIOLOGY AND DISEASE}

\section{Role of VNUT in the Regulation of Neuronal Differentiation and Neuritogenesis}

Differentiation of the axon is a pivotal process that gives rise to a complex morphology and physiology of neurons. Axon formation and growth is regulated by a variety of extracellular mediators, such as neurotransmitters, neurotrophic factors and other signaling molecules. Stimulating cultured hippocampal neurons with ATP evokes $\mathrm{Ca}^{2+}$ transients in the distal part of the axon which exerts a negative effect on axon growth, reducing both axonal length and branching (Diaz-Hernandez et al., 2008). This effect is mediated through P2X7 receptors that are expressed at the growth cone of the axon. Either the pharmacological inhibition of P2X7 receptor or its silencing by shRNA results in longer and more-branched axons, which is coupled to morphological changes of the growth cone (Diaz-Hernandez et al., 2008). This effect of ATP on axonal growth was corroborated by the finding that tissue-nonspecific alkaline phosphatase (TNAP) regulates axonal elongation and branching in hippocampal neurons by controlling the local availability of growth-inhibiting extracellular ATP (Diez-Zaera et al., 2011). Moreover, $\mathrm{P} 2 \mathrm{X} 7$ receptors negatively regulate neurite formation in mouse Neuro-2a (N2a) neuroblastoma cell line (Gomez-Villafuertes et al., 2009). Pharmacological inhibition and interference of $\mathrm{P} 2 \mathrm{X} 7$ receptor expression were associated with neuritogenesis in N2a cells, whereas P2X7 overexpression significantly reduced neurite formation. Neurotrophic effects of P2X7 were mediated through the modulation of the activity of the $\mathrm{Ca}^{2+} /$ calmodulin-dependent kinase II and some of its downstream effectors, which have been related to axonal growth and neuronal differentiation processes (Gomez-Villafuertes et al., 2009). Thus, N2a cells have been shown to be a suitable model to analyze the sequence of purinergic events that regulate neuronal differentiation.

Although N2a cells express very small amounts of endogenous VNUT, this transporter can be successfully heterologously expressed in this cell line, and co-localization of VNUT with the vesicular marker synaptophysin could be observed by confocal microscopy imaging (Menendez-Mendez et al., 2015). Retinoic acid-induced differentiation keeps VNUT expression in transfected N2a cells. Functionality of the vesicular transporter was assessed by luciferin-luciferase assays to measure ionomycin-induced ATP release from differentiated N2a cells (Menendez-Mendez et al., 2015). Expression of VNUT clearly decreases neuritogenesis in retinoic acid-treated N2a cells, as both the number and length of neurites are reduced when compared to control (VNUT non-expressing) cells. To corroborate the VNUT negative effect on neuritogenesis, shVNUT was used to knockdown VNUT expression in VNUT-transfected and differentiated cells. These cells, where VNUT expression was reduced, showed more prominent neuritogenesis, with an increase in both the number and length of neurites. These results highlight the role of VNUT as a key component in the sequence of events involved in extracellular ATP regulation of neuritogenesis and neuronal differentiation processes (Menendez-Mendez et al., 2015).

\section{VNUT in the Spinal Cord: Role of VNUT-Dependent ATP Release in Neuropathic Pain}

In the spinal cord, VNUT has been related to neuropathic pain, a hypersensitivity to pain that occurs after damage of a peripheral nerve as a consequence of traumatic injury or diseases such as diabetes mellitus, multiple sclerosis or cancer. Accumulating evidence indicated the crucial role of microglial cells in the spinal cord in the development of neuropathic pain. After damage of a peripheral nerve, spinal microglia turn into a reactive state through a sequence of molecular and 
cellular changes, which include the increase in the expression of genes that encode purinergic receptors, such as P2X 4 or $\mathrm{P} 2 \mathrm{Y}_{12}$. In response to the activation of these ATP receptors, microglial cells release different bioactive factors that cause abnormal neurotransmission in the nociceptive network in spinal dorsal horn (SDH). These pathological alterations result in pain hypersensitivity that converts initially innocuous stimuli into nociceptive signals (Tsuda et al., 2003; Tozaki-Saitoh et al., 2008).

Spinal dorsal horn neurons have been identified as a source of extracellular ATP that contributes to peripheral nerve injury (PNI) induced pain hypersensitivity (Masuda et al., 2016). PNI increases VNUT expression in the spinal cord and this upregulation of VNUT is required for the development of tactile allodynia (abnormal pain hypersensitivity evoked by innocuous stimuli), as the intrathecal administration of siRNA targeting VNUT in mice subjected to PNI, significantly reduced the expression of spinal VNUT and ameliorated PNI-evoked allodynia. Moreover, PNI also increased extracellular ATP content within the spinal cord and this increase was suppressed by vesicular exocytosis inhibitors (Masuda et al., 2016). VNUT-deficient $\left(V_{N U T}^{-/-}\right)$mice did not shown PNI-evoked increase in extracellular ATP concentration and had attenuated pain hypersensitivity. Attenuation of PNI-induced allodynia and reduction in spinal extracellular ATP content was also observed in mice with specific deletion of VNUT in SDH neurons, but not in mice lacking VNUT in primary sensory neurons, astrocytes or microglia. Moreover, ectopic expression of VNUT in SDH neurons of VNUT-deficient mice restored PNI-evoked increase in extracellular ATP and pain. These results showed that VNUT-dependent exocytotic ATP release from dorsal horn neurons is an essential mechanism for neuropathic pain after PNI (Masuda et al., 2016).

Vesicular nucleotide transporter is expressed in subpopulations of rat dorsal root ganglion (DRG) neurons (Nishida et al., 2014). In a model of rats subjected to nerve injury (L5 spinal nerve ligation), an increase in VNUT expression was observed in injured DRG neurons. Moreover, VNUT co-localize with the lysosomal protein LAMP1 in these cells (Jung et al., 2016). Fluorescent labeling of lysosomal vesicles demonstrated that ATP containing VNUT-positive lysosomes are transported to the central nerve terminals of DRG neurons in the dorsal horn. Although there is no direct evidence of ATP release from primary afferent nerve terminals in dorsal horn through lysosomal exocytosis, a previous in vitro study revealed exocytotic ATP release from lysosomes in primary cultured DRG neurons (Jung et al., 2013). In the light of these findings, it has been suggested that lysosomal exocytosis from central terminals of DRG neurons could be an additional source of ATP that contribute to activation of the microglia in the dorsal horn after nerve injury (Jung et al., 2016).

Vesicular nucleotide transporter shows strong similarities with other members of the family of SCL17 anion transporters, such as the vesicular glutamate transporter (VGLUT). VGLUT undergoes unusual regulation by $\mathrm{Cl}^{-}$. Glutamate uptake into vesicles shows biphasic dependence with the concentration of this ion: low $\mathrm{Cl}^{-}$concentrations $(2-8 \mathrm{mM})$ stimulate glutamate transport while high concentrations $(>20 \mathrm{mM})$ inhibit it. It has been suggested that $\mathrm{Cl}^{-}$acts as an allosteric modulator of VGLUT that triggers glutamate uptake upon binding to the transporter (Juge et al., 2010), whereas the inhibition of vesicular glutamate accumulation by high $\mathrm{Cl}^{-}$concentrations could be related to the dissipation of $\Delta \psi$, the component of $\Delta \mu \mathrm{H}^{+}$that drives vesicular glutamate uptake. However, the precise molecular mechanism underlying the regulation of VGLUT by $\mathrm{Cl}^{-}$is still to be clarified. Ketone bodies inhibit vesicular glutamate transport by competing with $\mathrm{Cl}^{-}$at the site of allosteric regulation (Juge et al., 2010), which suggest a metabolic control of vesicular glutamate release. The strong dependence on transport activity with $\mathrm{Cl}^{-}$concentration is a characteristic shared by other members of the SLC17 family such as VNUT. Presence of this ion is an absolute requirement for ATP transport activity in VNUT, as nucleotide transport cannot be detected in the absence of $\mathrm{Cl}^{-} \cdot \mathrm{Br}^{-}$also activates transport, whereas $\mathrm{I}^{-}, \mathrm{F}^{-}$, nitrate, sulfate, and thiocyanate are ineffective (Sawada et al., 2008). This anion dependence is very similar to that of VGLUT2 (Juge et al., 2010). Moreover, VNUT is also inhibited by ketone bodies such as acetoacetate (Figure 1B), the inhibitory effect being reversible and prevented by high concentrations of $\mathrm{Cl}^{-}$(Juge et al., 2010). Although detailed kinetic studies have not been carried out, these findings suggest the existence of similar anion binding sites and regulatory mechanisms in both members of the SLC17 family of transporters, VNUT and VGLUT.

Clodronate is a first-generation bisphosphonate used in antiresorptive therapy for osteoporosis. Nevertheless, studies have proved that clodronate also has analgesic properties, although the mechanism underlying this analgesic effect was unknown. Recently, clodronate was identified as a potent and selective inhibitor of ATP vesicular storage and release (Figure 1B; Kato et al., 2017). In vitro assays demonstrated that clodronate inhibits VNUT $\left(\mathrm{IC}_{50}=15.6 \mathrm{nM}\right)$ without affecting other vesicular neurotransmitter transporters, acting as an allosteric modulator that interacts with the $\mathrm{Cl}^{-}$binding site. Clodronate shifted the $\mathrm{Cl}^{-}$concentration necessary for VNUT activation toward a higher activation level, suggesting a competitive interaction. Consistent with this, clodronate modulates vesicular ATP release. Low concentrations of clodronate completely inhibited ATP release from microglia, neurons and immune cells (human monocyte cell line THP-1). In vivo analysis revealed that clodronate attenuates neuropathic and inflammatory pain, in addition to the accompanying inflammation, in wild type but no $V N U T^{-/-}$mice, without altering basal nociception (Kato et al., 2017). These results demonstrated that clodronate exerts analgesic and antiinflammatory actions by targeting VNUT. Noticeably, clodronate is approved for clinical use in the treatment of osteoporosis and its clinical safety in humans is well established (Muratore et al., 2011). Moreover, clodronate attenuates inflammatory and neuropathic pain with stronger, faster acting, and longer lasting effects than existing drugs (Kato et al., 2017; Moriyama and Nomura, 2018). Thereby, clodronate is likely to be clinically useful in the treatment of chronic neuropathic pain and could 
open new perspectives regarding the use of VNUT inhibitors that block vesicular ATP release as therapeutic drugs.

\section{VNUT in the Retina: Possible Role of VNUT in the Development of Glaucoma}

Using laser microdissected retinal samples, VNUT mRNA expression was detected in photoreceptor and inner nuclear layer/ganglion cell layer (INL/GCL) samples (Vessey and Fletcher, 2012). Immunochemical studies have shown that VNUT appear to be widely distributed throughout the inner and outer retinal layers, with particular strong immunoreactivity detected in the outer segments of photoreceptors, outer plexiform layer, inner plexiform layer and ganglion cell layer. Presence of VNUT in these retinal areas was confirmed by the loss of VNUT immunoreactivity in the retina from VNUT knockout $\left(V_{N U T}{ }^{-/}\right)$mice (Moriyama and Hiasa, 2016). Double-labeling immunochemistry showed that VNUT is co-localized with synaptophysin and VGLUT1 in photoreceptor cells, whereas it is co-localized with vesicular $\gamma$-aminobutyric acid (GABA) transporter (VGAT) in bipolar and amacrine cells. VNUT is also present in astrocytes and Müller cells. Retinal membrane fraction took up radiolabeled ATP in a DIDS and bafilomycin A1 (a vacuolar ATPase inhibitor) sensitive manner, this ATP-uptake activity being absent in retinal membrane vesicles prepared from $V N U T^{-/-}$mice (Moriyama and Hiasa, 2016). Thus, these results indicate that VNUT is widely present in retina, where ATP can be stored and released to initiate purinergic chemical transmission.

Vesicular nucleotide transporter immunoreactivity can be detected in $\mathrm{TH}$ positive dopaminergic amacrine/interplexiform cells (Ho et al., 2015). Three-dimensional reconstruction of retinal flatmounts immunolabelled with VNUT showed that VNUT-positive amacrine/plexiform cells processes are closely associated with cone photoreceptors terminals and horizontal cells, which are known to express P2 purinergic receptors. In order to assess function, dissociated retinal neurons were loaded with fluorescent dopamine (FFN102) and ATP (MANT-ATP, quinacrine) markers and immunostained with a VNUT antibody. VNUT-immunoreactive neurons load fluorescent ATP and dopamine markers in vesicles. Moreover, ATP and dopamine markers co-localize in these cells, thus indicating co-loading of ATP and dopamine in vesicles within the VNUT-positive neurons. Fluorescence of the ATP marker quinacrine was reduced upon $\mathrm{K}^{+}$stimulation, this response being blocked in the presence of cadmium. Taken together, all these results indicate that dopaminergic neurons in the retina release ATP via calcium dependent exocytosis, which may modulate the visual response by stimulating purinergic receptors in closely associated cells (Ho et al., 2015).

Retinal extracellular ATP levels and changes in VNUT expression have been analyzed in the DBA/2J mouse model of glaucoma during the development of the disease (Perez de Lara et al., 2015). For this purpose, retinas were dissected from glaucomatous animals at 3, 9, 15, and 22 months of age. C57BL/6J mice were used as age-matched controls. Retinal net ATP release increased with the progression of the pathology, varying from $0.32 \mathrm{pmol} /$ retina (3 months) to $1.10 \mathrm{pmol} / \mathrm{retina}$ (15 months, threefold increase). Concomitantly, a significant increase in VNUT expression in DBA/2J mice retina during glaucoma progression was detected. These data may suggest a possible correlation between retinal dysfunction and increased levels of extracellular ATP and nucleotide transporter (Perez de Lara et al., 2015).

TABLE 1 | Expression, localization, and function of VNUT in the central nervous system.

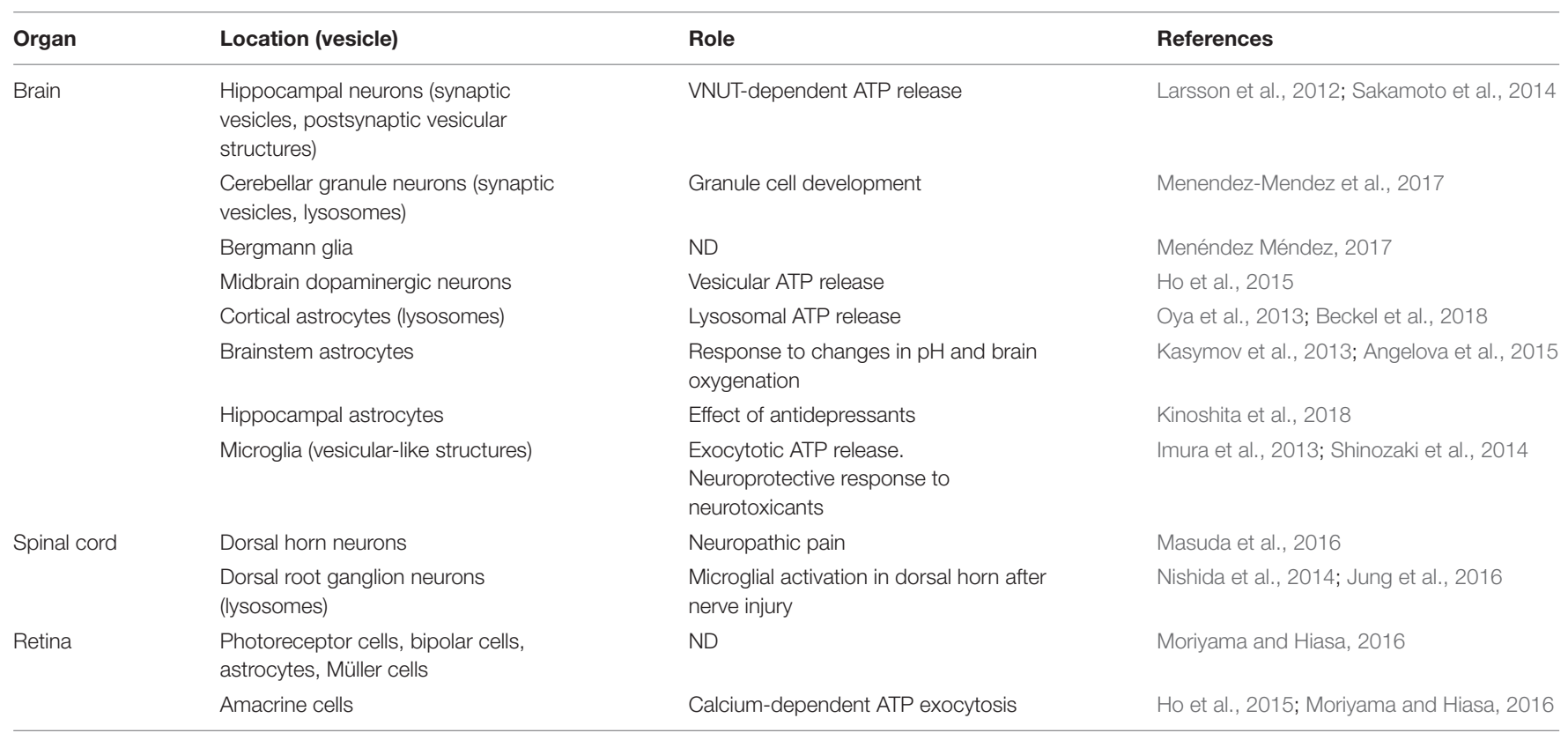

ND, not determined. 


\section{CONCLUDING REMARKS}

It is widely accepted that VNUT is responsible for the storage of ATP and other nucleotides into secretory vesicles and therefore plays an essential role in the vesicular release of nucleotides and the initiation of purinergic chemical transmission. Both the reduction in the expression of VNUT and the inhibition of its activity reduce the vesicular release of ATP and lead to a decrease in purinergic chemical signaling. VNUT appear to be widely expressed in the central nervous system, being present in neurons, astrocytes and microglial cells. Accumulating evidence indicate the involvement of VNUT-dependent nucleotide release in a diversity of biological processes in the central nervous system, which include development of the cerebellar cortex, neuronal differentiation and neuritogenesis, sensing of physiological changes in $\mathrm{pH}$ and brain oxygenation, protection against neurotoxicants or modulation of depressive behaviors. The expression pattern, localization and functions of VNUT in the central nervous system are summarized in Table 1. Deficiencies in the vesicular release of ATP could have beneficial effects in certain pathological conditions. In particular, increased levels of extracellular ATP have correlated with retinal dysfunction during the development of glaucoma. Moreover, mice deficient in VNUT show attenuated neuropathic pain, and the selective inhibitor

\section{REFERENCES}

Abbracchio, M. P., Burnstock, G., Verkhratsky, A., and Zimmermann, H. (2009). Purinergic signalling in the nervous system: an overview. Trends Neurosci. 32, 19-29. doi: 10.1016/j.tins.2008.10.001

Aberer, W., Kostron, H., Huber, E., and Winkler, H. (1978). A characterization of the nucleotide uptake of chromaffin granules of bovine adrenal medulla. Biochem. J. 172, 353-360. doi: 10.1042/bj1720353b

Alcock, J., Lowe, J., England, T., Bath, P., and Sottile, V. (2009). Expression of Sox1, Sox2 and Sox9 is maintained in adult human cerebellar cortex. Neurosci. Lett. 450, 114-116. doi: 10.1016/j.neulet.2008.11.047

Amadio, S., Montilli, C., Picconi, B., Calabresi, P., and Volonte, C. (2007). Mapping P2X and P2Y receptor proteins in striatum and substantia nigra: an immunohistological study. Purinergic Signal. 3, 389-398. doi: 10.1007/s11302007-9069-8

Angelova, P. R., Kasymov, V., Christie, I., Sheikhbahaei, S., Turovsky, E., Marina, N., et al. (2015). Functional oxygen sensitivity of astrocytes. J. Neurosci. 35, 10460-10473. doi: 10.1523/JNEUROSCI.0045-15.2015

Bankston, L. A., and Guidotti, G. (1996). Characterization of ATP transport into chromaffin granule ghosts. synergy of ATP and serotonin accumulation in chromaffin granule ghosts. J. Biol. Chem. 271, 17132-17138. doi: 10.1074/jbc. 271.29.17132

Baroja-Mazo, A., Barbera-Cremades, M., and Pelegrin, P. (2013). The participation of plasma membrane hemichannels to purinergic signaling. Biochim. Biophys. Acta 1828, 79-93. doi: 10.1016/j.bbamem.2012.01.002

Beckel, J. M., Gomez, N. M., Lu, W., Campagno, K. E., Nabet, B., Albalawi, F., et al. (2018). Stimulation of TLR3 triggers release of lysosomal ATP in astrocytes and epithelial cells that requires TRPML1 channels. Sci. Rep. 8:5726. doi: 10.1038/s41598-018-23877-3

Blakely, R. D., and Edwards, R. H. (2012). Vesicular and plasma membrane transporters for neurotransmitters. Cold Spring Harb. Perspect. Biol. 4:a005595. doi: 10.1101/cshperspect.a005595

Bowser, D. N., and Khakh, B. S. (2007). Vesicular ATP is the predominant cause of intercellular calcium waves in astrocytes. J. Gen. Physiol. 129, 485-491. doi: 10.1085/jgp.200709780

Burnstock, G. (2007a). Physiology and pathophysiology of purinergic neurotransmission. Physiol. Rev. 87, 659-797. doi: 10.1152/physrev.00043.2006 of VNUT, clodronate, exerts analgesic effects. Therefore, VNUT could constitute a new and relevant molecular target in the context of the pathophysiology of purinergic transmission. Impairment of purinergic signaling by inhibiting the activity of VNUT or silencing VNUT gene expression may represent a new and promising therapeutical strategy for the treatment of a variety of pathological conditions.

\section{AUTHOR CONTRIBUTIONS}

JG wrote the manuscript and made illustrations. MM-P, AM-M, RG-V, FO, ED, and RP-S wrote the manuscript.

\section{FUNDING}

This work was supported by the Spanish Ministerio de Economia y Competitividad (MINECO, BFU 2014-53654-P) and the "Red de Excelencia Consolider-Ingenio Spanish Ion Channel Initiative" (BFU2015-70067REDC), by the Comunidad de Madrid (BRADE-CM S2013/ICE-2958), and by a Fundación Ramón Areces Grant (PR2018/16-02). FO is the recipient of a Ramón y Cajal contract (RYC-2013-13290).

Burnstock, G. (2007b). Purine and pyrimidine receptors. Cell. Mol. Life Sci. 64, 1471-1483.

Burnstock, G., Krugel, U., Abbracchio, M. P., and Illes, P. (2011). Purinergic signalling: from normal behaviour to pathological brain function. Prog. Neurobiol. 95, 229-274. doi: 10.1016/j.pneurobio.2011.08.006

Cachope, R., and Cheer, J. F. (2014). Local control of striatal dopamine release. Front. Behav. Neurosci. 8:188. doi: 10.3389/fnbeh.2014.00188

Calovi, S., Mut-Arbona, P., and Sperlagh, B. (2018). Microglia and the purinergic signaling system. Neuroscience 405, 137-147. doi: 10.1016/j.neuroscience.2018. 12.021

Cao, X., Li, L. P., Wang, Q., Wu, Q., Hu, H. H., Zhang, M., et al. (2013). Astrocytederived ATP modulates depressive-like behaviors. Nat. Med. 19, 773-777. doi: $10.1038 / \mathrm{nm} .3162$

Chaudhry, F. A., Edwards, R. H., and Fonnum, F. (2008). Vesicular neurotransmitter transporters as targets for endogenous and exogenous toxic substances. Annu. Rev. Pharmacol. Toxicol. 48, 277-301. doi: 10.1146/annurev.pharmtox.46.120604.141146

Chen, J., Tan, Z., Zeng, L., Zhang, X., He, Y., Gao, W., et al. (2013). Heterosynaptic long-term depression mediated by ATP released from astrocytes. Glia 61, 178-191. doi: 10.1002/glia.22425

Chinta, S. J., and Andersen, J. K. (2005). Dopaminergic neurons. Int. J. Biochem. Cell Biol. 37, 942-946. doi: 10.1016/j.biocel.2004.09.009

Coco, S., Calegari, F., Pravettoni, E., Pozzi, D., Taverna, E., Rosa, P., et al. (2003). Storage and release of ATP from astrocytes in culture. J. Biol. Chem. 278, 1354-1362. doi: 10.1074/jbc.M209454200

Diaz-Hernandez, M., del Puerto, A., Diaz-Hernandez, J. I., Diez-Zaera, M., Lucas, J. J., Garrido, J. J., et al. (2008). Inhibition of the ATPgated P2X7 receptor promotes axonal growth and branching in cultured hippocampal neurons. J. Cell. Sci. 121(Pt 22), 3717-3728. doi: 10.1242/jcs. 034082

Diez-Zaera, M., Diaz-Hernandez, J. I., Hernandez-Alvarez, E., Zimmermann, H., Diaz-Hernandez, M., and Miras-Portugal, M. T. (2011). Tissue-nonspecific alkaline phosphatase promotes axonal growth of hippocampal neurons. Mol. Biol. Cell. 22, 1014-1024. doi: 10.1091/mbc.E10-09-0740

Dou, Y., Wu, H. J., Li, H. Q., Qin, S., Wang, Y. E., Li, J., et al. (2012). Microglial migration mediated by ATP-induced ATP release from lysosomes. Cell Res. 22, 1022-1033. doi: $10.1038 / \mathrm{cr} .2012 .10$ 
Eiden, L. E., Schafer, M. K., Weihe, E., and Schutz, B. (2004). The vesicular amine transporter family (SLC18): amine/proton antiporters required for vesicular accumulation and regulated exocytotic secretion of monoamines and acetylcholine. Pflugers Arch. 447, 636-640. doi: 10.1007/s00424-003-1100-5

Gasnier, B. (2004). The SLC32 transporter, a key protein for the synaptic release of inhibitory amino acids. Pflugers Arch. 447, 756-759. doi: 10.1007/s00424-0031091-2

Gomez-Villafuertes, R., del Puerto, A., Diaz-Hernandez, M., Bustillo, D., DiazHernandez, J. I., Huerta, P. G., et al. (2009). Ca2+/calmodulin-dependent kinase II signalling cascade mediates P2X7 receptor-dependent inhibition of neuritogenesis in neuroblastoma cells. FEBS J. 276, 5307-5325. doi: 10.1111/ j.1742-4658.2009.07228.x

Gualix, J., Abal, M., Pintor, J., Garcia-Carmona, F., and Miras-Portugal, M. T. (1996). Nucleotide vesicular transporter of bovine chromaffin granules. Evidence for a mnemonic regulation. J. Biol. Chem. 271, 1957-1965. doi: $10.1074 /$ jbc.271.4.1957

Gualix, J., Alvarez, A. M., Pintor, J., and Miras-Portugal, M. T. (1999a). Studies of chromaffin granule functioning by flow cytometry: transport of fluorescent epsilon-ATP and granular size increase induced by ATP. Receptors Channels 6, 449-461.

Gualix, J., Pintor, J., and Miras-Portugal, M. T. (1999b). Characterization of nucleotide transport into rat brain synaptic vesicles. J. Neurochem. 73, 10981104. doi: 10.1046/j.1471-4159.1999.0731098.x

Gualix, J., Fideu, M. D., Pintor, J., Rotllan, P., Garcia-Carmona, F., and Miras-Portugal, M. T. (1997). Characterization of diadenosine polyphosphate transport into chromaffin granules from adrenal medulla. FASEB J. 11, 981-990. doi: 10.1096/fasebj.11.12.9337151

Gualix, J., Gomez-Villafuertes, R., Pintor, J., Llansola, M., Felipo, V., and Miras-Portugal, M. T. (2014). Presence of diadenosine polyphosphates in microdialysis samples from rat cerebellum in vivo: effect of mild hyperammonemia on their receptors. Purinergic Signal. 10, 349-356. doi: 10. 1007/s11302-013-9382-3

Ho, T., Jobling, A. I., Greferath, U., Chuang, T., Ramesh, A., Fletcher, E. L., et al. (2015). Vesicular expression and release of ATP from dopaminergic neurons of the mouse retina and midbrain. Front. Cell. Neurosci. 9:389. doi: 10.3389/fncel. 2015.00389

Holmsen, H., and Weiss, H. J. (1979). Secretable storage pools in platelets. Annu. Rev. Med. 30, 119-134. doi: 10.1146/annurev.me.30.020179.001003

Hracsko, Z., Baranyi, M., Csolle, C., Goloncser, F., Madarasz, E., Kittel, A., et al. (2011). Lack of neuroprotection in the absence of P2X7 receptors in toxininduced animal models of parkinson's disease. Mol. Neurodegener. 6:28. doi: 10.1186/1750-1326-6-28

Hutton, J. C., Penn, E. J., and Peshavaria, M. (1983). Low-molecular-weight constituents of isolated insulin-secretory granules. Bivalent cations, adenine nucleotides and inorganic phosphate. Biochem. J. 210, 297-305. doi: 10.1042/ bj2100297

Imura, Y., Morizawa, Y., Komatsu, R., Shibata, K., Shinozaki, Y., Kasai, H., et al. (2013). Microglia release ATP by exocytosis. Glia 61, 1320-1330. doi: 10.1002/ glia.22517

Jo, Y. H., and Schlichter, R. (1999). Synaptic corelease of ATP and GABA in cultured spinal neurons. Nat. Neurosci. 2, 241-245. doi: 10.1038/6344

Johnson, R. G. Jr. (1988). Accumulation of biological amines into chromaffin granules: a model for hormone and neurotransmitter transport. Physiol. Rev. 68, 232-307. doi: 10.1152/physrev.1988.68.1.232

Joshua, M., Adler, A., and Bergman, H. (2009). The dynamics of dopamine in control of motor behavior. Curr. Opin. Neurobiol. 19, 615-620. doi: 10.1016/ j.conb.2009.10.001

Juge, N., Gray, J. A., Omote, H., Miyaji, T., Inoue, T., Hara, C., et al. (2010). Metabolic control of vesicular glutamate transport and release. Neuron 68, 99-112. doi: 10.1016/j.neuron.2010.09.002

Jung, J., Shin, Y. H., Konishi, H., Lee, S. J., and Kiyama, H. (2013). Possible ATP release through lysosomal exocytosis from primary sensory neurons. Biochem. Biophys. Res. Commun. 430, 488-493. doi: 10.1016/j.bbrc.2012. 12.009

Jung, J., Uesugi, N., Jeong, N. Y., Park, B. S., Konishi, H., and Kiyama, H. (2016). Increase of transcription factor EB (TFEB) and lysosomes in rat DRG neurons and their transportation to the central nerve terminal in dorsal horn after nerve injury. Neuroscience 313, 10-22. doi: 10.1016/j.neuroscience.2015. 11.028

Kasymov, V., Larina, O., Castaldo, C., Marina, N., Patrushev, M., Kasparov, S., et al. (2013). Differential sensitivity of brainstem versus cortical astrocytes to changes in $\mathrm{pH}$ reveals functional regional specialization of astroglia. J. Neurosci. 33, 435-441. doi: 10.1523/JNEUROSCI.2813-12.2013

Kato, Y., Hiasa, M., Ichikawa, R., Hasuzawa, N., Kadowaki, A., Iwatsuki, K., et al. (2017). Identification of a vesicular ATP release inhibitor for the treatment of neuropathic and inflammatory pain. Proc. Natl. Acad. Sci. U.S.A. doi: 10.1073/ pnas.1704847114 [Epub ahead of print].

Kettenmann, H., Hanisch, U. K., Noda, M., and Verkhratsky, A. (2011). Physiology of microglia. Physiol. Rev. 91, 461-553. doi: 10.1152/physrev.00011. 2010

Kinoshita, M., Hirayama, Y., Fujishita, K., Shibata, K., Shinozaki, Y., Shigetomi, E., et al. (2018). Anti-Depressant fluoxetine reveals its therapeutic effect via astrocytes. EBioMedicine 32, 72-83. doi: 10.1016/j.ebiom.2018.05.036

Kostron, H., Winkler, H., Peer, L. J., and Konig, P. (1977). Uptake of adenosine triphosphate by isolated adrenal chromaffin granules: a carrier-mediated transport. Neuroscience 2, 159-166. doi: 10.1016/0306-4522(77)90077-x

Lalo, U., Palygin, O., Rasooli-Nejad, S., Andrew, J., Haydon, P. G., and Pankratov, Y. (2014). Exocytosis of ATP from astrocytes modulates phasic and tonic inhibition in the neocortex. PLoS Biol. 12:e1001747. doi: 10.1371/journal.pbio. 1001747

Larsson, M., Sawada, K., Morland, C., Hiasa, M., Ormel, L., Moriyama, Y., et al. (2012). Functional and anatomical identification of a vesicular transporter mediating neuronal ATP release. Cereb. Cortex 22, 1203-1214. doi: 10.1093/ cercor/bhr203

Lazarowski, E. R. (2012). Vesicular and conductive mechanisms of nucleotide release. Purinergic Signal. 8, 359-373. doi: 10.1007/s11302-012-9304-9

Lein, E. S., Hawrylycz, M. J., Ao, N., Ayres, M., Bensinger, A., Bernard, A., et al. (2007). Genome-wide atlas of gene expression in the adult mouse brain. Nature 445, 168-176. doi: 10.1038/nature05453

Liu, G. J., Kalous, A., Werry, E. L., and Bennett, M. R. (2006). Purine release from spinal cord microglia after elevation of calcium by glutamate. Mol. Pharmacol. 70, 851-859. doi: 10.1124/mol.105.021436

Liu, H. T., Toychiev, A. H., Takahashi, N., Sabirov, R. Z., and Okada, Y. (2008). Maxi-anion channel as a candidate pathway for osmosensitive ATP release from mouse astrocytes in primary culture. Cell Res. 18, 558-565. doi: 10.1038/cr. 2008.49

Liu, J., Liu, W., and Yang, J. (2016). ATP-containing vesicles in stria vascular marginal cell cytoplasms in neonatal rat cochlea are lysosomes. Sci. Rep. 6:20903. doi: $10.1038 /$ srep20903

Luqmani, Y. A. (1981). Nucleotide uptake by isolated cholinergic synaptic vesicles: evidence for a carrier of adenosine $5^{\prime}$-triphosphate. Neuroscience 6, 1011-1021. doi: 10.1016/0306-4522(81)90067-1

Ma, Y., Cao, W., Wang, L., Jiang, J., Nie, H., Wang, B., et al. (2014). Basal CD38/cyclic ADP-ribose-dependent signaling mediates ATP release and survival of microglia by modulating connexin 43 hemichannels. Glia 62, $943-$ 955. doi: 10.1002/glia.22651

Masuda, T., Ozono, Y., Mikuriya, S., Kohro, Y., Tozaki-Saitoh, H., Iwatsuki, K., et al. (2016). Dorsal horn neurons release extracellular ATP in a VNUTdependent manner that underlies neuropathic pain. Nat. Commun. 7:12529. doi: $10.1038 /$ ncomms 12529

Menéndez Méndez, A. (2017). Caracterización Del Transportador Vesicular De Nucleótidos En Tejidos Neurales. Ph.D. thesis, Complutense University of Madrid, Madrid.

Menendez-Mendez, A., Diaz-Hernandez, J. I., and Miras-Portugal, M. T. (2015). The vesicular nucleotide transporter (VNUT) is involved in the extracellular ATP effect on neuronal differentiation. Purinergic Signal. 11, 239-249. doi: 10.1007/s11302-015-9449-4

Menendez-Mendez, A., Diaz-Hernandez, J. I., Ortega, F., Gualix, J., GomezVillafuertes, R., and Miras-Portugal, M. T. (2017). Specific temporal distribution and subcellular localization of a functional vesicular nucleotide transporter (VNUT) in cerebellar granule neurons. Front. Pharmacol. 8:951. doi: 10.3389/fphar.2017.00951

Morin, N., and Di Paolo, T. (2014). Interaction of adenosine receptors with other receptors from therapeutic perspective in Parkinson's disease. 
Int. Rev. Neurobiol. 119, 151-167. doi: 10.1016/B978-0-12-801022-8. 00007-6

Moriyama, S., and Hiasa, M. (2016). Expression of vesicular nucleotide transporter in the mouse retina. Biol. Pharm. Bull. 39, 564-569. doi: 10.1248/bpb.b1500872

Moriyama, Y., Hiasa, M., Sakamoto, S., Omote, H., and Nomura, M. (2017). Vesicular nucleotide transporter (VNUT): appearance of an actress on the stage of purinergic signaling. Purinergic Signal. 13, 387-404. doi: 10.1007/s11302017-9568-1

Moriyama, Y., and Nomura, M. (2018). Clodronate: a vesicular ATP release blocker. Trends Pharmacol. Sci. 39, 13-23. doi: 10.1016/j.tips.2017. 10.007

Muratore, M., Quarta, E., Grimaldi, A., Calcagnile, F., and Quarta, L. (2011). Clinical utility of clodronate in the prevention and management of osteoporosis in patients intolerant of oral bisphosphonates. Drug Des. Devel. Ther. 5, 445454. doi: 10.2147/DDDT.S12139

Nakagomi, H., Yoshiyama, M., Mochizuki, T., Miyamoto, T., Komatsu, R., Imura, Y., et al. (2016). Urothelial ATP exocytosis: regulation of bladder compliance in the urine storage phase. Sci. Rep. 6:29761. doi: 10.1038/ srep29761

Newman, E. A. (2003). Glial cell inhibition of neurons by release of ATP. J. Neurosci. 23, 1659-1666. doi: 10.1523/jneurosci.23-05-01659.2003

Nishida, K., Nomura, Y., Kawamori, K., Moriyama, Y., and Nagasawa, K. (2014). Expression profile of vesicular nucleotide transporter (VNUT, SLC17A9) in subpopulations of rat dorsal root ganglion neurons. Neurosci. Lett. 579, 75-79. doi: 10.1016/j.neulet.2014.07.017

Njus, D., Kelley, P. M., and Harnadek, G. J. (1986). Bioenergetics of secretory vesicles. Biochim. Biophys. Acta 853, 237-265. doi: 10.1016/0304-4173(87) 90003-6

Omote, H., Miyaji, T., Hiasa, M., Juge, N., and Moriyama, Y. (2016). Structure, function, and drug interactions of neurotransmitter transporters in the postgenomic era. Annu. Rev. Pharmacol. Toxicol. 56, 385-402. doi: 10.1146/ annurev-pharmtox-010814-124816

Omote, H., and Moriyama, Y. (2013). Vesicular neurotransmitter transporters: an approach for studying transporters with purified proteins. Physiology 28, 39-50. doi: 10.1152/physiol.00033.2012

Orriss, I. R., Knight, G. E., Utting, J. C., Taylor, S. E., Burnstock, G., and Arnett, T. R. (2009). Hypoxia stimulates vesicular ATP release from rat osteoblasts. J. Cell. Physiol. 220, 155-162. doi: 10.1002/jcp.21745

Oya, M., Kitaguchi, T., Yanagihara, Y., Numano, R., Kakeyama, M., Ikematsu, K., et al. (2013). Vesicular nucleotide transporter is involved in ATP storage of secretory lysosomes in astrocytes. Biochem. Biophys. Res. Commun. 438, 145-151. doi: 10.1016/j.bbrc.2013.07.043

Pangrsic, T., Potokar, M., Stenovec, M., Kreft, M., Fabbretti, E., Nistri, A., et al. (2007). Exocytotic release of ATP from cultured astrocytes. J. Biol. Chem. 282, 28749-28758. doi: 10.1074/jbc.M700290200

Pankratov, Y., Lalo, U., Verkhratsky, A., and North, R. A. (2006). Vesicular release of ATP at central synapses. Pflugers Arch. 452, 589-597. doi: 10.1007/s00424006-0061-X

Pankratov, Y., Lalo, U., Verkhratsky, A., and North, R. A. (2007). Quantal release of ATP in mouse cortex. J. Gen. Physiol. 129, 257-265.doi: 10.1085/jgp.20060 9693

Parpura, V., and Zorec, R. (2010). Gliotransmission: exocytotic release from astrocytes. Brain Res. Rev. 63, 83-92. doi: 10.1016/j.brainresrev.2009.11.008

Pascual, O., Casper, K. B., Kubera, C., Zhang, J., Revilla-Sanchez, R., Sul, J. Y., et al. (2005). Astrocytic purinergic signaling coordinates synaptic networks. Science 310, 113-116. doi: 10.1126/science.1116916

Perez de Lara, M. J., Guzman-Aranguez, A., de la Villa, P., Diaz-Hernandez, J. I., Miras-Portugal, M. T., and Pintor, J. (2015). Increased levels of extracellular ATP in glaucomatous retinas: possible role of the vesicular nucleotide transporter during the development of the pathology. Mol. Vis. 21,1060-1070.

Pintor, J., Diaz-Rey, M. A., Torres, M., and Miras-Portugal, M. T. (1992a). Presence of diadenosine polyphosphates-Ap4A and Ap5A-in rat brain synaptic terminals. Ca2 + dependent release evoked by 4 -aminopyridine and veratridine. Neurosci. Lett. 136, 141-144. doi: 10.1016/0304-3940(92)90034-5

Pintor, J., Kowalewski, H. J., Torres, M., Mirasportugal, M. T., and Zimmermann, H. (1992b). Synaptic vesicle storage of diadenosine polyphosphates in the torpedo electric organ. Neurosci. Res. Commun. 10, 9-15.
Pintor, J., Rotllan, P., Torres, M., and Miras-Portugal, M. T. (1992c). Characterization and quantification of diadenosine hexaphosphate in chromaffin cells: granular storage and secretagogue-induced release. Anal. Biochem. 200, 296-300. doi: 10.1016/0003-2697(92)90469-n

Reimer, R. J. (2013). SLC17: a functionally diverse family of organic anion transporters. Mol. Aspects Med. 34, 350-359. doi: 10.1016/j.mam.2012.05.004

Richardson, P. J., and Brown, S. J. (1987). ATP release from affinity-purified rat cholinergic nerve terminals. J. Neurochem. 48, 622-630. doi: 10.1111/j.14714159.1987.tb04138.x

Rodriguez del Castillo, A., Torres, M., Delicado, E. G., and Miras-Portugal, M. T. (1988). Subcellular distribution studies of diadenosine polyphosphatesAp4A and Ap5A-in bovine adrenal medulla: presence in chromaffin granules. J. Neurochem. 51, 1696-1703. doi: 10.1111/j.1471-4159.1988. tb01147.x

Roseth, S., Fykse, E. M., and Fonnum, F. (1995). Uptake of L-glutamate into rat brain synaptic vesicles: effect of inhibitors that bind specifically to the glutamate transporter. J. Neurochem. 65, 96-103. doi: 10.1046/j.1471-4159. 1995.65010096.x

Sakamoto, S., Miyaji, T., Hiasa, M., Ichikawa, R., Uematsu, A., Iwatsuki, K., et al. (2014). Impairment of vesicular ATP release affects glucose metabolism and increases insulin sensitivity. Sci. Rep. 4:6689. doi: 10.1038/srep06689

Sawada, K., Echigo, N., Juge, N., Miyaji, T., Otsuka, M., Omote, H., et al. (2008). Identification of a vesicular nucleotide transporter. Proc. Natl. Acad. Sci. U.S.A. 105, 5683-5686. doi: 10.1073/pnas.0800141105

Sawynok, J., Downie, J. W., Reid, A. R., Cahill, C. M., and White, T. D. (1993). ATP release from dorsal spinal cord synaptosomes: characterization and neuronal origin. Brain Res. 610, 32-38. doi: 10.1016/0006-8993(93)91213-c

Shinozaki, Y., Nomura, M., Iwatsuki, K., Moriyama, Y., Gachet, C., and Koizumi, S. (2014). Microglia trigger astrocyte-mediated neuroprotection via purinergic gliotransmission. Sci. Rep. 4:4329. doi: 10.1038/srep04329

Sottile, V., Li, M., and Scotting, P. J. (2006). Stem cell marker expression in the bergmann glia population of the adult mouse brain. Brain Res. 1099, 8-17. doi: 10.1016/j.brainres.2006.04.127

Stout, C. E., Costantin, J. L., Naus, C. C., and Charles, A. C. (2002). Intercellular calcium signaling in astrocytes via ATP release through connexin hemichannels. J. Biol. Chem. 277, 10482-10488. doi: 10.1074/jbc.M109902200

Suadicani, S. O., Brosnan, C. F., and Scemes, E. (2006). P2X7 receptors mediate ATP release and amplification of astrocytic intercellular $\mathrm{Ca} 2+$ signaling. J. Neurosci. 26, 1378-1385. doi: 10.1523/JNEUROSCI.3902-05.2006

Suadicani, S. O., Iglesias, R., Wang, J., Dahl, G., Spray, D. C., and Scemes, E. (2012). ATP signaling is deficient in cultured Pannexin1-null mouse astrocytes. Glia 60, 1106-1116. doi: 10.1002/glia.22338

Tompkins, J. D., and Parsons, R. L. (2006). Exocytotic release of ATP and activation of $\mathrm{P} 2 \mathrm{X}$ receptors in dissociated guinea pig stellate neurons. Am. J. Physiol. Cell Physiol. 291, C1062-C1071. doi: 10.1152/ajpcell.00472.2005

Tozaki-Saitoh, H., Tsuda, M., Miyata, H., Ueda, K., Kohsaka, S., and Inoue, K. (2008). P2Y12 receptors in spinal microglia are required for neuropathic pain after peripheral nerve injury. J. Neurosci. 28, 4949-4956. doi: 10.1523/ JNEUROSCI.0323-08.2008

Tsuda, M., Shigemoto-Mogami, Y., Koizumi, S., Mizokoshi, A., Kohsaka, S., Salter, M. W., et al. (2003). P2X4 receptors induced in spinal microglia gate tactile allodynia after nerve injury. Nature 424, 778-783. doi: 10.1038/nature01786

Verderio, C., Cagnoli, C., Bergami, M., Francolini, M., Schenk, U., Colombo, A., et al. (2012). TI-VAMP/VAMP7 is the SNARE of secretory lysosomes contributing to ATP secretion from astrocytes. Biol. Cell. 104, 213-228. doi: 10.1111/boc. 201100070

Vessey, K. A., and Fletcher, E. L. (2012). Rod and cone pathway signalling is altered in the P2X7 receptor knock out mouse. PLoS One 7:e29990. doi: 10.1371/ journal.pone.0029990

Weber, A., and Winkler, H. (1981). Specificity and mechanism of nucleotide uptake by adrenal chromaffin granules. Neuroscience 6, 2269-2276. doi: 10.1016/03064522(81)90016-6

Whittaker, V. P. (1987). Cholinergic synaptic vesicles from the electromotor nerve terminals of torpedo. Composition and life cycle. Ann. N. Y. Acad. Sci. 493, 77-91. doi: 10.1111/j.1749-6632.1987.tb27185.x

Winkler, H. (1976). The composition of adrenal chromaffin granules: an assessment of controversial results. Neuroscience 1, 65-80. doi: 10.1016/0306-4522(76) 90001-4 
Wise, R. A. (2008). Dopamine and reward: the anhedonia hypothesis 30 years on. Neurotox. Res. 14, 169-183. doi: 10.1007/ BF03033808

Zhang, J. M., Wang, H. K., Ye, C. Q., Ge, W., Chen, Y., Jiang, Z. L., et al. (2003). ATP released by astrocytes mediates glutamatergic activity-dependent heterosynaptic suppression. Neuron 40, 971-982. doi: 10.1016/s0896-6273(03) 00717-7

Zhang, Z., Chen, G., Zhou, W., Song, A., Xu, T., Luo, Q., et al. (2007). Regulated ATP release from astrocytes through lysosome exocytosis. Nat. Cell Biol. 9, 945-953. doi: 10.1038/ ncb 1620
Conflict of Interest Statement: The authors declare that the research was conducted in the absence of any commercial or financial relationships that could be construed as a potential conflict of interest.

Copyright $\odot 2019$ Miras-Portugal, Menéndez-Méndez, Gómez-Villafuertes, Ortega, Delicado, Pérez-Sen and Gualix. This is an open-access article distributed under the terms of the Creative Commons Attribution License (CC BY). The use, distribution or reproduction in other forums is permitted, provided the original author(s) and the copyright owner(s) are credited and that the original publication in this journal is cited, in accordance with accepted academic practice. No use, distribution or reproduction is permitted which does not comply with these terms. 